\title{
A queda da desnutrição infantil no Brasil
}

Nos últimos anos, o Brasil experimentou um dos mais impressionantes declínios da desnutrição infantil já registrados em todo o mundo em desenvolvimento. A comparação de estimativas de inquéritos do programa Demographic Health Surveys realizados em amostras probabilísticas da população brasileira de menores de cinco anos em 1996 e em 2006/2007 mostra que formas graves de desnutrição, indicadas pela desproporção acentuada entre peso e altura, foram virtualmente eliminadas de todo o país, incluindo a Região Nordeste, onde estas formas de desnutrição ainda eram relevantes. No mesmo período, a prevalência nacional de déficits de altura para idade, indicador sensível da presença persistente de más condições de alimentação e de saúde, foi reduzida de 13,5\% para 6,8\%. No Nordeste, o retardo de crescimento declinou de $22,2 \%$ para $5,9 \%$, eliminando totalmente a tradicional desvantagem desta região com as do centro-sul do país. A intensa queda no retardo de crescimento entre o quinto das crianças com menor renda e a modesta redução observada no quinto com maior renda eliminou três quartas partes da disparidade absoluta existente entre a extrema pobreza e a extrema riqueza (de 24,6 para 6,2 pontos percentuais).

Modelagens estatísticas aplicadas ao conjunto de informações dos dois inquéritos indicam que a evolução favorável de quatro determinantes da nutrição infantil justificaria dois terços do declínio observado na desnutrição [Monteiro et al. Rev Saúde Pública 2009; 43(1):35-43]. A melhoria na escolaridade materna, particularmente a duplicação da proporção de mães que cursaram o primeiro grau completo, explicaria $25,7 \%$ do declínio na prevalência do retardo de crescimento na infância. Outros $21,7 \%$ poderiam ser atribuídos ao aumento do poder aquisitivo das famílias brasileiras mais pobres, refletido na substancial migração da classe E para as classes D e C de consumo. Adicionais 11,6\% do declínio seriam atribuídos à expansão de cuidados básicos de saúde a mães e crianças, e outros $4,3 \%$ ao crescimento da cobertura dos serviços de saneamento. Em suma, as causas subjacentes ao notável declínio da desnutrição infantil no Brasil parecem residir em melhorias na cobertura de serviços públicos essenciais e em aumentos da renda familiar, ambos favorecendo especialmente os mais pobres.

Cumpre reconhecer que a melhoria no perfil de escolaridade das mães responde à expansão do acesso de jovens ao Ensino Fundamental ocorrida há 10 ou 20 anos. Já as melhorias na assistência à saúde materno-infantil e no saneamento representam ampliações contínuas do acesso a estes serviços havidas ao longo do período 1996-2007. Por outro lado, o aumento expressivo do poder aquisitivo dos mais pobres é de ocorrência mais recente, decorrendo do reaquecimento da economia nacional, da redução do desemprego e de políticas dirigidas para o aumento da renda dos mais pobres, em particular a elevação do salário mínimo e a expansão e intensificação dos programas de transferência de renda [Neri MC, coord. Miséria, Desigualdade e Políticas de Renda: O Real do Lula. Rio de Janeiro: FGV/IBRE/CPS; 2007].

De qualquer sorte, e mais importante: a superação definitiva do flagelo da desnutrição infantil, vislumbrada no último decênio, dependerá tanto da manutenção do crescimento econômico e das políticas de redistribuição de renda quanto de investimentos na universalização, ainda não completada, do acesso de todas as famílias brasileiras à educação, saúde e saneamento.

A experiência brasileira na última década demonstra o enorme impacto que políticas de redistribuição de renda e de acesso universal à educação, saúde e saneamento podem ter sobre a desnutrição infantil. Tais políticas deveriam estar no topo da agenda de prioridades de qualquer governo comprometido com a melhoria da qualidade de vida das futuras gerações.

Carlos Augusto Monteiro

Faculdade de Saúde Pública, Universidade de São Paulo, São Paulo, Brasil.

carlosam@usp.br 